\title{
Effect of Exercise on Left Atrial Mechanical Functions in Professional Wrestlers
}

\author{
Hasan Güngör, Alper Kartal', Abraham Samuel Babu², Sercan Çayırlı, Esin Ergin ${ }^{1}$ \\ Departments of Cardiology and ${ }^{1}$ Movement and Training, Adnan Menderes University, Aydin, Turkey, ${ }^{2}$ Department of Physiotherapy, Manipal College of Health \\ Professions, Manipal Academy of Higher Edcuation, Manipal, Karnataka, India \\ ORCID: \\ Hasan Güngör: https://orcid.org/0000-0002-4462-3029 \\ Alper Kartal: https://orcid.org/0000-0001-5209-5134 \\ Abraham Samuel Babu: https://orcid.org/0000-0003-1084-0137 \\ Sercan Çayırll: https://orcid.org/0000-0001-9660-9993 \\ Esin Ergin: https://orcid.org/0000-0002-9645-1863
}

\section{Abstract}

Background: The adaptation of the cardiovascular system to exercise differs according to the type of sport. The aim of this study is to evaluate the effect of regular exercise on left atrial (LA) mechanical functions in professional wrestlers at internationally competitive level versus controls. Methods: Twenty professional male wrestlers (mean age, $21.90+2.49$ years) and twenty male controls (mean age, $22.3+1.49$ years) participated in this study. Echocardiographic assessments were performed using the criteria of the American Society of Echocardiography. The following LA volumes (LAVs) were measured: maximal volume $\left(\mathrm{V}_{\max }\right)$, minimal volume $\left(\mathrm{V}_{\min }\right)$, and LAV before atrial contraction $\left(\mathrm{V}_{\text {preA }}\right)$ at the onset of the pulsed wave of the simultaneously recorded electrocardiogram. LA ejection fraction (LAEF), LA expansion index (LAEI), LA active emptying volume index (LAAEVI) and fraction (LAAEFr), and LA passive emptying volume index (LAPEVI) and fraction (LAPEFr) were calculated. Results: Body mass index and LA diameter were statistically significantly higher in the wrestlers' group $(P<0.05)$. Other baseline characteristics, demographics, and echocardiographic parameters did not show any statistically significant difference between the groups. With regard to LAVs, $\mathrm{V}_{\min }$ index and $\mathrm{V}_{\text {preA }}$ index were lower in wrestlers $(P<0.05)$, whereas LAEF, LAPEVI, and LAPEFr were higher in wrestlers' groups $(P<0.05)$. LAEI, LAAEVI, and LAAEFr were higher in wrestlers but were not statistically significant. Conclusion: Wrestling may be associated with morphologic alterations in LA mechanical functions. Deterioration in the mechanical function of the LA can be detected even earlier, especially if the volume is preserved in the early period.

Keywords: Exercise, left atrium, mechanical function, wrestler

\section{INTRODUCTION}

It is now well established that participation in long-term, hard exercise is associated with morphological alterations in the heart, resulting in what is known as "athlete's heart." The athlete's heart also includes physiologic alterations such as bradycardia and increased stroke volume. ${ }^{[1-3]}$ Cardiac adaptations vary with the type of sport and intensity of exercise. For example, endurance sports such as soccer and long-distance running have a higher dynamic component, whereas wrestling has a higher static or isometric component.

Received: 30-11-2019 Revised: 22-01-2020 Accepted: 04-02-2020

Published Online: 11-06-2020

\begin{tabular}{|l|l|}
\hline \multicolumn{3}{c|}{ Access this article online } \\
\hline Quick Response Code: & Website: \\
& http:/www.ijcva.com \\
& \\
\hline
\end{tabular}

Sports with high dynamic and low static demands lead to eccentric hypertrophy of the left ventricle (LV), whereas sports with high static demands lead to concentric LV hypertrophy. ${ }^{[4,5]}$

Even though the changes in LV have been greatly focused, the change in the left atrium (LA) cannot be excluded considering the series connection of the LA and LV. It has been observed that in highly trained athletes, there is also a

Address for correspondence: Dr. Hasan Güngör, Department of Cardiology, Faculty of Medicine, Adnan Menderes University, Aydin 09100, Turkey. E-mail: drgungorhasan@yahoo.com

This is an open access journal, and articles are distributed under the terms of the Creative Commons Attribution-NonCommercial-ShareAlike 4.0 License, which allows others to remix, tweak, and build upon the work non-commercially, as long as appropriate credit is given and the new creations are licensed under the identical terms.

For reprints contact: WKHLRPMedknow_reprints@wolterskluwer.com

How to cite this article: Güngör H, Kartal A, Babu AS, Çayırlı S, Ergin E. Effect of exercise on left atrial mechanical functions in professional wrestlers. Int J Cardiovasc Acad 2020;6:70-4. 
mild LA enlargement that is frequently seen. ${ }^{[6]}$ As the LV and LA are so closely connected, any impairment in LV can alter the LA function, resulting in atrial myopathy. Furthermore, the LA immediately responds to changes in LV end-diastolic pressure, which suggests that LA remodeling is common and LA mechanical functions are commonly impaired in the setting of altered LV mechanics. ${ }^{[7,8]}$ Despite the evidence available on the role of LA as a determinant in LV filling in various cardiovascular diseases (including heart failure), ${ }^{[9,10]}$ there is limited information on how it would be affected among high-demand, isometric sports (e.g., professional wrestlers). Thus, the aim of this study was to evaluate LA mechanical functions among professional wrestlers at an international competitive level and compare them against healthy controls.

\section{Methods}

\section{Study population}

The present research was approved by the local noninterventional Clinical Research Ethics Committee (decision no. 11, dated: 26.05.2016). Twenty professional male wrestlers (mean age, $21.90+2.49$ years) and twenty male controls (mean age, $22.3+1.49$ years) participated in this study. International wrestlers for this study were defined as wrestlers who had participated in international wrestling at a competitive level. Controls were recruited from healthy members of students and were matched for age and height and were not performing any regular physical exercise. Regular exercise is defined as $120 \mathrm{~min}$ a day, 5 days a week. Healthy volunteers and professional wrestlers were enrolled after obtaining written and verbal informed consent.

\section{Conventional echocardiographic examination}

Echocardiographic examinations were performed at rest, using the iE33 cardiac ultrasound system (Phillips Healthcare, Philips, Best, The Netherlands) with $2.5-5 \mathrm{MHz}$ probes. The evaluation was performed as per the American Society of Echocardiography guidelines. Simultaneous electrocardiogram (ECG) recordings were performed for all patients during the examination. Doppler and tissue Doppler measurements were performed to estimate various parameters of LV systolic and diastolic function. The peak LV outflow velocity was evaluated using continuous-wave Doppler in the apical four-chamber view using the modified Bernoulli equation. Mitral inflow velocities were studied using pulsed-wave (PW) Doppler after placing the sample volume at the leaflets' tips. The peak early (E-wave) and late (A-wave) velocities were also measured. Both septal and lateral mitral annular velocities were obtained using tissue Doppler imaging. The Eheelocity was obtained from the septal and lateral annular En velocities, and the ratio of the mitral inflow E velocity to average tissue Doppler velocity (E/E'av) was calculated for the prediction of LV filling pressure.

\section{Assessment of left atrial mechanical functions}

LA volumes (LAVs) were calculated in four- and two-chamber views by Simpson's rule. The endocardial border of the LA was manually traced to measure its area. Maximal volume $\left(\mathrm{V}_{\max }\right)$ at the end of the QRS complex, minimal volume $\left(\mathrm{V}_{\text {min }}\right)$ at the end of the PW, and LAV before atrial contraction $\left(\mathrm{V}_{\text {pres }}\right)$ at the onset of the PW of the simultaneously recorded ECG with echocardiography were obtained [Figures 1-3]. LAV was indexed to body surface area (BSA), and LAV index (LAVI) was calculated by indexing $\mathrm{V}_{\text {max }}$ to BSA. LAVs were obtained as the mean of three consecutive beats. Other variables such as LA ejection fraction (LAEF), LA expansion index (LAEI), LA active emptying volume index (LAAEVI) and fraction (LAAEFr), and LA passive emptying volume index (LAPEVI) and fraction (LAPEFr) were calculated. Intraobserver and interobserver measurement variability for $\mathrm{V}_{\max }, \mathrm{V}_{\text {min }}$, and $\mathrm{V}_{\text {preA }}$ yielded an average coefficient of variation of $5.5 \%$ and $5.2 \%, 5.3 \%$ and $5.7 \%$, and $4.8 \%$ and $5.4 \%$, respectively.

\section{Calculation of left atrial mechanical functions}

LAEF and LAEI were used for the assessment of the LA reservoir function, LAPEFr for the conduit function, and LAAEFr for the booster pump function. Various other LA functions were estimated using the following formulae:

1. $\mathrm{LAEF}$ defined as $\left.\left(\mathrm{V}_{\max }-\mathrm{V}_{\min }\right) / \mathrm{V}_{\max } \times 100 \%\right)$

2. LAEI defined as $\left.\left(\mathrm{V}_{\text {max }}-\mathrm{V}_{\text {min }}\right) / \mathrm{V}_{\text {min }} \times 100 \%\right)$

3. LA active emptying volume (LAAEV) defined as $\left(\mathrm{V}_{\text {preA }}-\mathrm{V}_{\text {min }}\right)$

4. LA active emptying fraction (LAAEFr) defined as $\left(\mathrm{LAAEV} / \mathrm{V}_{\mathrm{preA}} \times 100 \%\right)$

5. LA passive emptying volume (LAPEV) defined as $\left(\mathrm{V}_{\text {max }}-\mathrm{V}_{\text {preA }}\right)$

6. LA passive emptying fraction (LAPEFr) defined as $\left(\mathrm{LAPEV} / \mathrm{V}_{\text {max }} \times 100 \%\right)$.

\section{Statistical analysis}

All results were analyzed by using Statistical Package for Social Sciences for Windows (version 18.0; SPSS Inc., Chicago, IL, USA). Continuous data were reported as mean and standard deviation or median, if not normally distributed, and compared using the Student's $t$-test or the Mann-Whitney U-test between

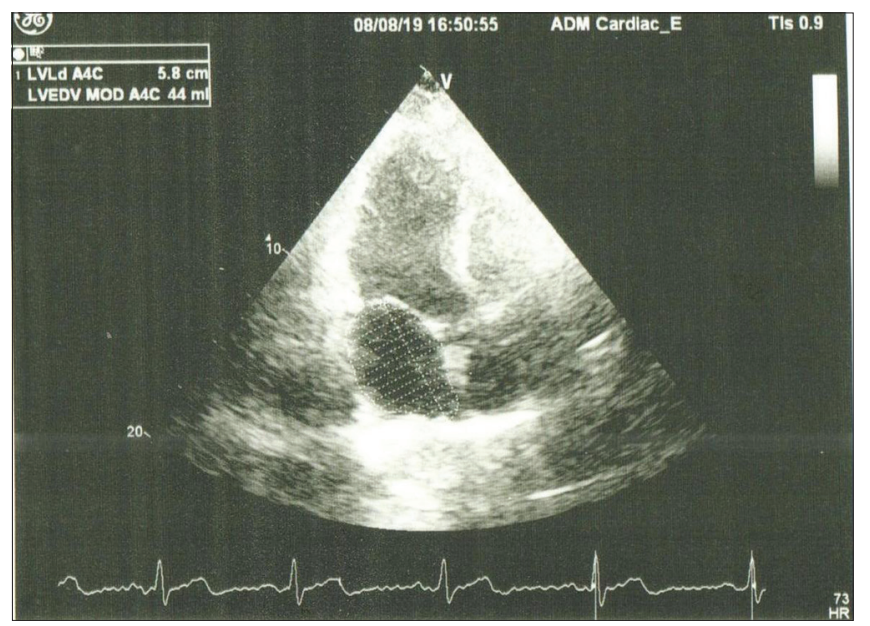

Figure 1: Left atrial maximal volume 


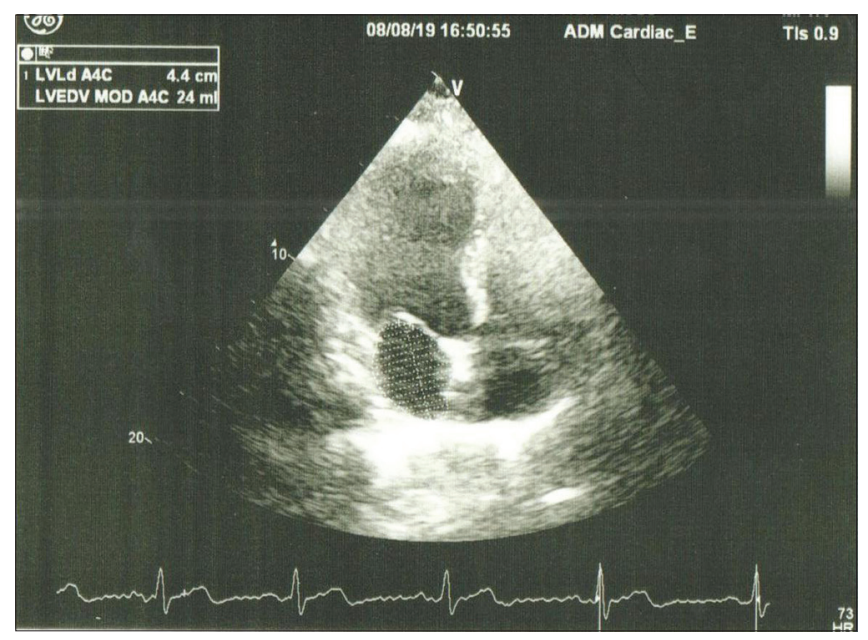

Figure 2: Left atrial minimal volume

groups. Categorical variables were summarized as percentages and compared with the Chi-square test. A two-tailed $P<0.05$ was considered statistically significant.

\section{RESULTS}

Body mass index $\left(27.27+4.82\right.$ vs. $24.74+3.59 \mathrm{~kg} / \mathrm{m}^{2}$, $P=0.026)$ and LA diameter $(33.85+8.25$ vs. $31.05+2.91 \mathrm{~mm}$, $P=0.005)$ were significantly higher in wrestlers' group as compared to the healthy controls. Other baseline characteristics, demographics, and two-dimensional and tissue Doppler echocardiographic parameters were similar between the groups $([P>0.05]$ [Tables 1 and 2$])$.

A summary of the LAV measurements is presented in Table 3. Both groups were similar in terms of $\mathrm{V}_{\text {max }}$ index, but $\mathrm{V}_{\text {min }}$ index and $\mathrm{V}_{\text {preA }}$ index were significantly lower in wrestlers. In terms of function, LAEF, LAPEVI, and LAPEFr were significantly higher among the wrestlers. However, although higher in wrestlers, LAEI, LAAEVI, and LAAEFr measures were not statistically significant $(P>0.05)$. No changes in LV and right ventricular ejection fraction were observed.

\section{Discussion}

Adaptations to high-intensity exercise have been well documented in the athlete's heart. ${ }^{[11]}$ However, the documentation of the changes in the LA among professional wrestlers is novel and unique. Elevation in LV filling pressure and an increase in LV wall thickness have been suggested as potential activators to LA enlargement. ${ }^{[7]}$ This study found changes in the LA similar to what has been documented in previous studies and supports the claim that atrial enlargement is the result of adaptation to the high blood flow induced by high-intensity training. ${ }^{[12]}$ Increased size of the LA has been found to be a predictor of arrhythmias (atrial fibrillation) among highly trained athletes. ${ }^{[13]}$ The higher LA size among wrestlers suggests that these individuals could be at greater risk for atrial fibrillation. However, this is yet to be studied in this population. Whether the change in training patterns and

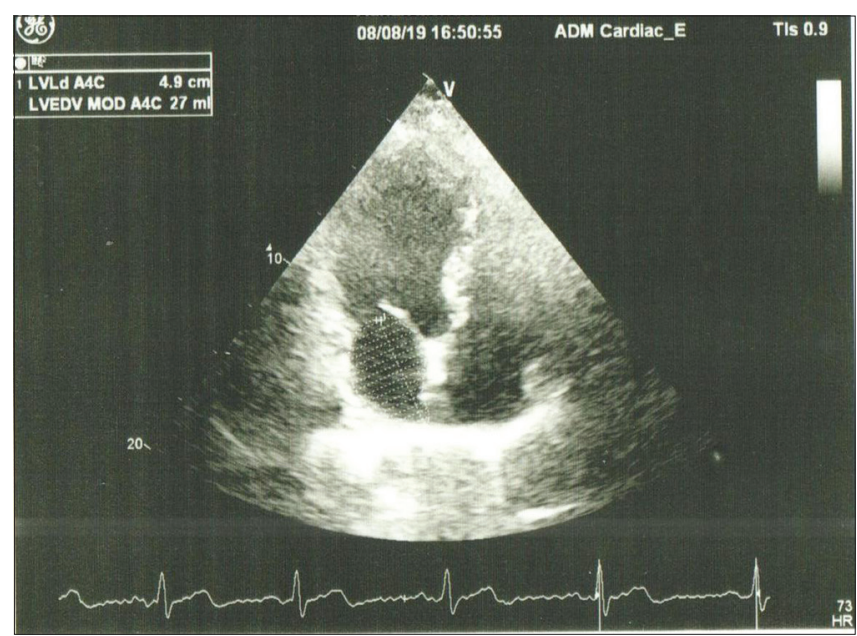

Figure 3: Left atrial before atrial contraction volume

\begin{tabular}{lccc}
\hline \multicolumn{4}{l}{ Table 1: Baseline characteristics and demographics } \\
\hline Variables & $\begin{array}{c}\text { Control group } \\
(\boldsymbol{n}=\mathbf{2 0})\end{array}$ & $\begin{array}{c}\text { Wrestlers } \\
(\boldsymbol{n = 2 0 )}\end{array}$ & $\boldsymbol{P}$ \\
& $22.3 \pm 1.49$ & $21.90 \pm 2.49$ & 0.205 \\
\hline Age (years) & $24.74 \pm 3.59$ & $27.27 \pm 4.82$ & $0.026^{*}$ \\
BMI $\left(\mathrm{kg} / \mathrm{m}^{2}\right)$ & $1.96 \pm 0.22$ & $2.00 \pm 0.23$ & 0.710 \\
BSA $\left(\mathrm{m}^{2}\right)$ & $66.80 \pm 14.30$ & $72.25 \pm 11.03$ & 0.072 \\
Heart rate (beats/min) & $117.50 \pm 13.12$ & $117.25 \pm 8.03$ & 0.476 \\
Systolic BP (mmHg) & $75.75 \pm 5.68$ & $79.75 \pm 4.72$ & 0.059 \\
Diastolic BP (mmHg)
\end{tabular}

BMI: body mass index, BSA: body surface area. Statistically significant findings are highlighted with $(*)$

\section{Table 2: Two dimensional and tissue Doppler echocardiographic parameters}

\begin{tabular}{lccc}
\hline Variables & $\begin{array}{c}\text { Control group } \\
(\boldsymbol{n}=\mathbf{2 0})\end{array}$ & $\begin{array}{c}\text { Wrestlers } \\
(\boldsymbol{n}=\mathbf{2 0})\end{array}$ & $\boldsymbol{P}$ \\
\hline Left atrium diameter (mm) & $31.05 \pm 2.91$ & $33.85 \pm 8.25$ & $0.005^{*}$ \\
LVSED (mm) & $30.65 \pm 3.77$ & $30.15 \pm 3.08$ & 0.206 \\
LVEDD (mm) & $47.60 \pm 5.26$ & $46.75 \pm 4.99$ & 0.123 \\
Septum thickness (mm) & $9.85 \pm 1.22$ & $8.95 \pm 1.64$ & 0.137 \\
Posterior wall thickness (mm) & $9.55 \pm 1.46$ & $9.30 \pm 1.26$ & 0.794 \\
Right ventricle (mm) & $26.25 \pm 3.78$ & $26.70 \pm 2.62$ & 0.399 \\
LVEF & $65.45 \pm 5.09$ & $67.20 \pm 2.65$ & 0.311 \\
RVEF & $64.85 \pm 0.67$ & $64.96+0.64$ & 0.312 \\
LV mass (g) & $188.38 \pm 56.20$ & $169.81 \pm 65.16$ & 0.130 \\
E (m/sn) & $0.80 \pm 0.21$ & $0.81 \pm 0.13$ & 0.908 \\
A (m/sn) & $0.55 \pm 0.13$ & $0.53 \pm 0.12$ & 0.863 \\
E/E' septal & $5.41 \pm 1.58$ & $6.70 \pm 1.91$ & 0.063 \\
E/E' lateral & $4.13 \pm 1.21$ & $5.06 \pm 1.74$ & 0.308 \\
\hline LV: Left vns
\end{tabular}

LV: Left ventricular, LVESD: Left ventricular end-systolic diameter, LVEDD: Left ventricular end-diastolic diameter, LVEF: Left ventricular ejection fraction, RVEF: Right ventricular ejection fraction. Statistically significant findings are highlighted with $(*)$

methods could have an impact on the risk of atrial fibrillation without affecting the outcome of the competitive sport is yet to be seen. ${ }^{[14]}$ This suggests that these individuals would require regular cardiology examinations and follow-up. 


\begin{tabular}{lcc}
\hline Table 3: Measurements of left atrial mechanical functions & \\
\hline Variables & Control group $(\boldsymbol{n = 2 0})$ & Wrestlers $(\boldsymbol{n = 2 0})$ \\
\hline Vmax index $\left(\mathrm{ml} / \mathrm{m}^{2}\right)$ & $23.97 \pm 5.66$ & $27.83 \pm 7.64$ \\
Vmin index $\left(\mathrm{ml} / \mathrm{m}^{2}\right)$ & $10.15 \pm 2.99$ & $10.04 \pm 3.52$ \\
VpreA index $\left(\mathrm{ml} / \mathrm{m}^{2}\right)$ & $14.84 \pm 4.13$ & $13.22 \pm 4.42$ \\
LA ejection fraction (\%) & $56.65 \pm 9.73$ & 6.060 \\
LA expansion index (\%) & $145.15 \pm 42.13$ & $164.95 \pm 48.48$ \\
LA active emptying volume index $\left(\mathrm{ml} / \mathrm{m}^{2}\right)$ & $4.69 \pm 2.81$ & $5.35 \pm 2.90$ \\
LA active emptying fraction $(\%)$ & $30.00 \pm 13.16$ & $38.50 \pm 17.40$ \\
LA passive emptying volume index $\left(\mathrm{ml} / \mathrm{m}^{2}\right)$ & $9.12 \pm 3.20$ & $13.94 \pm 6.10$ \\
LA passive emptying fraction $(\%)$ & $38.50 \pm 11.10$ & $45.70 \pm 17.74$ \\
\hline
\end{tabular}

LA: left atrium, Vmax: left atrium maximum volume, Vmin: left atrium minimum volume, VpreA: left atrium volume before $P$ wave. Statistically significant findings are highlighted with $(*)$

The present study showed that participation in high-demand, isometric sports, as in professional wrestlers, affects LA mechanical functions. To the best of our knowledge, there is no previous study investigating the LA mechanical functions in wrestlers of international competitive level versus healthy controls. This study found higher total and passive emptying volume indices among wrestlers when compared to healthy controls. These findings are similar to those reported in other studies among other professional athletes. ${ }^{[12,15]}$

In the current clinical practice, LA enlargement is common in certain conditions due to the immediate response to changing LV end-diastolic pressures. ${ }^{[7]}$ Similar mechanisms could exist in wrestlers, and it is shown that $\mathrm{V}_{\text {min }}$ index and $\mathrm{V}_{\text {pres }}$ index were significantly lower in wrestlers. Anwar et al. showed that the $\mathrm{LAV}_{\max }, \mathrm{V}_{\text {min }}$, and $\mathrm{V}_{\text {preA }}$ are larger in wrestlers when compared to controls. ${ }^{[7]}$ The remodeling effects on the LA and the LV dynamics may be the result of repetitive isometric strength training among wrestlers.

A previous study has shown that a mild-to-moderate increase in LAV causes an increase in LA contractility; however, a further increase in LA preload does not enhance the LA pump function, but rather leads to functional failure of the LA. ${ }^{[16]}$ This could be contributed by the training methods, which suggests that there could be a considerable impact on the method of training seen in wrestlers. The impact of training on LA size was recently summarized in a review which found that any form of training (endurance, resistance, or combined) increased LA size. ${ }^{[17]}$ The altered LA size further impacts the LA emptying fractions as well, which was found to be higher among wrestlers than in healthy controls. This is contrary to the findings of Nemes et al., in which they reported total and active LA emptying fractions to be reduced in athletes as compared to controls. ${ }^{[15]}$ However, they studied professional basketball and handball players who have very different training regimes than wrestlers, which could have an impact on the findings. Nevertheless, the findings are similar to that of another study by D'Ascenzi et al., in which total and passive emptying volume indices were greater among athletes when compared to controls. ${ }^{[12]}$ In addition, the altered mechanics observed in this study are in agreement with the findings of D'Andrea et al. ${ }^{[18]}$ However, there continues to exist the controversy, which will require further study.
Wrestlers had larger LA diameter and higher LAEF, LAPEVI, and LAPEFr. LAV during the conduit phase increased in this group as well. In addition, LAEF is significantly higher and LAEI started to increase, although not statistically significant. Mechanical functions showing the booster pump functions as LAAEVI and LAAEFr were higher in wrestlers but not statistically significant. An interesting finding from the data in Table 3 is that conduit functions were initially impaired. This could be due to the immediate response of the LA (enlargement and mechanical function) to the change in LV end-diastolic pressure. This could be detected earlier if the volume has to be preserved.

In athletes, the data on the mechanical functions of the LA, other than dilation, are limited. D'Andrea et al. analyzed 615 consecutive professional athletes, which identified mildly enlarged LAVi in 150 athletes (24.3\%). LAVi was statistically significantly higher in endurance athletes $(P<0.01)$. However, in the overall population, the most powerful independent determinants of LAVi were type and duration of training and LV end-diastolic volume. ${ }^{[18]}$

The major limitation of our study is the lack of follow-up of wrestlers' and control groups for the risk of developing arrhythmias. Furthermore, the lack of speckle tracking and three-dimensional echocardiography for better assessment could be a factor further influencing the findings in addition to the small sample size. Further prospective trials with large number are necessary to show the effect of regular exercise to LA mechanical functions in wrestlers.

\section{Conclusion}

Professional wrestlers have altered LA function and mechanics as a result of their sport-specific training when compared to healthy controls. The impact of these changes on the risk of arrhythmias, as well as various training methods on LA function, is yet to be ascertained.

\section{Financial support and sponsorship}

Nil.

\section{Conflicts of interest}

There are no conflicts of interest. 


\section{References}

1. Sobhani V, Vahedi S, Farahani B, Bakhshi EA. Echocardiographic findings in professional wrestlers. Iranian Cardiovasc Res $\mathrm{J}$ 2010;4:123-6.

2. Maron BJ. Structural features of the athlete heart as defined by echocardiography. J Am Coll Cardiol 1986;7:190-203.

3. Blomqvist CG, Saltin B. Cardiovascular adaptations to physical training. Annu Rev Physiol 1983;45:169-89.

4. Fagard RH. Impact of different sports and training on cardiac structure and function. Cardiol Clin 1997;15:397-412.

5. Hoogsteen J, Hoogeveen A, Schaffers H, Wijn PF, van Hemel NM, van der Wall EE. Myocardial adaptation in different endurance sports: An echocardiographic study. Int J Cardiovasc Imaging 2004;20:19-26.

6. Pelliccia A, Maron BJ, di Paolo FM, Biffi A, Quattrini FM, Pisicchio C, et al. Prevalence and clinical significance of left atrial remodeling in competitive athletes. J Am Coll Cardiol 2005;46:690-6.

7. Anwar AM, Soliman OI, Nemes A, Geleijnse ML, ten Cate FJ. An integrated approach to determine left atrial volume, mass and function in hypertrophic cardiomyopathy by two-dimensional echocardiography. Int J Cardiovasc Imaging 2008;24:45-52.

8. Tülüce $\mathrm{K}$, Yakar Tülüce $\mathrm{S}$, Yavuzgil $\mathrm{O}$, İsayev $\mathrm{E}$, Bilgin $\mathrm{M}$, Akyıldız Akçay $\mathrm{F}$, et al. The left atrial phasic functions and the relationship with plasma $\mathrm{N}$-terminal pro-B-type natriuretic peptide levels and symptomatic states in patients with hypertrophic cardiomyopathy. Anadolu Kardiyol Derg 2014;14:719-27.

9. Suga $\mathrm{H}$. Importance of atrial compliance in cardiac performance. Circ Res 1974;35:39-43.
10. Abhayaratna WP, Fatema K, Barnes ME, Seward JB, Gersh BJ, Bailey KR, et al. Left atrial reservoir function as a potent marker for first atrial fibrillation or flutter in persons $>$ or $=65$ years of age. Am J Cardiol 2008;101:1626-9.

11. Iskandar A, Mujtaba MT, Thompson PD. Left Atrium Size in Elite Athletes. JACC Cardiovasc Imaging 2015;8:753-62.

12. D’Ascenzi F, Pelliccia A, Natali BM, Cameli M, Lisi M, Focardi M, et al. Training-induced dynamic changes in left atrial reservoir, conduit, and active volumes in professional soccer players. Eur J Appl Physiol 2015;115:1715-23.

13. Abdulla J, Nielsen JR. Is the risk of atrial fibrillation higher in athletes than in the general population? A systematic review and meta-analysis. Europace 2009;11:1156-9.

14. Sanchis-Gomar F, Lucia A. Pathophysiology of atrial fibrillation in endurance athletes: An overview of recent findings. CMAJ 2016;188:E433-E435.

15. Nemes A, Domsik P, Kalapos A, Orosz A, Oszlánczi M, Török L, et al. Volumetric and functional assessment of the left atrium in young competitive athletes without left ventricular hypertrophy: the MAGYAR -Sport Study. J Sports Med Phys Fitness 2017;57:900-6

16. Bauer F, Shiota T, White RD, Lever HM, Qin JX, Drinko J, et al. Determinant of left atrial dilation in patients with hypertrophic cardiomyopathy: A real-time 3-dimensional echocardiographic study. J Am Soc Echocardiogr 2004;17:968-75.

17. Kaur K. Effect of strength training on left atrium in wrestlers. Brazilian Journal of Biometricity 2013;7:139-43.

18. D’Andrea A, Bossone E, Radmilovic J, Riegler L, Pezzullo E, Scarafile R, et al. Exercise-Induced Atrial Remodeling: The Forgotten Chamber. Cardiol Clin 2016;34:557-65. 